\section{University of New Hampshire}

Carsey School of Public Policy

\section{CARSEY RESEARCH}

Regional Issue Brief \#64

\title{
Why People Move to and Stay in New Hampshire
}

Kenneth M. Johnson and Kristine Bundschuh

\section{Introduction}

Migration is important to New Hampshire's demographic future. Traditionally, the state has grown both because of migration into it and because of the surplus of births over deaths. That is no longer the case. More people died than were born in the state in 2017-2019, and all recent growth has been because of migration. ${ }^{1}$

Whether New Hampshire gains or loses migrants depends on three factors: how many people move into the state, how many leave, and how many stay. Factors that influence the decisions of any of these three groups of people contribute to the direction and magnitude of the state's migration gain or loss. In this brief, we examine why people choose to move to New Hampshire and why they continue to reside in the state.

New Hampshire has one of the most mobile populations in the United States. Just 44 percent of the populationand only 33 percent of those 25 and older-were born in the state; only six states have a smaller proportion of the population born within its borders. ${ }^{2}$ New Hampshire's population, therefore, mostly comprises people who migrated into the Granite State. Some migrants moved to the state recently, others long ago. Some are young families with children settling in the southern part of the state on the fringe of the Boston metropolitan area, and some are older adults attracted to recreational and retirement areas in central and northern New Hampshire.

Migration affects a population's composition as well as its size. New Hampshire's population is aging, as reflected in a significant increase in people above 50 years old in the past fifteen years. ${ }^{3}$ But because more young people have moved in than out in recent years, migration has helped to balance the state's age profile. The rising number of young people moving in between 2013 and 2017 has not only lowered the state's median age, it has also created the potential for additional children in the future as these migrants begin to have families. In addition, migration has brought an influx of better-educated, higher-income residents, ${ }^{4}$ increasing the state's human capital.

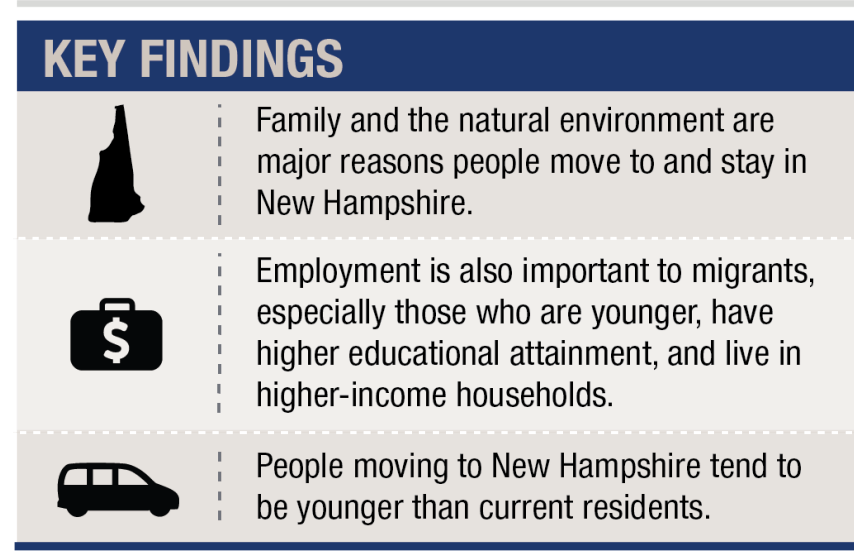

\section{Who Moves to New Hampshire and Who Stays?}

Because migration is important to New Hampshire's future, we analyzed data from the University of New Hampshire Survey Center's Granite State Poll to examine the characteristics of two groups of current New Hampshire residents. The first group is recent migrants - those who moved to New Hampshire in the past ten years-and we examine their motivations for moving to the state. The second group, established residents, are people who have lived in New Hampshire for more than ten years, including lifelong residents and people who moved to New Hampshire more than ten years ago. Among these long-term residents, we examine their motivations for continuing to reside in the state.

Recent migrants and established residents have similar demographic patterns. ${ }^{5}$ Over a third of each group lives in a household with an income of $\$ 100,000$ or more, and a significant proportion have earned a college degree or higher, including 42 percent of recent migrants and 37 percent of established 
residents (Figure 1). Most of the recent migrants and established residents are concentrated in the metropolitan areas of Hillsborough, Rockingham, and Strafford Counties. These sample results are generally consistent with Census Bureau estimates. ${ }^{6}$

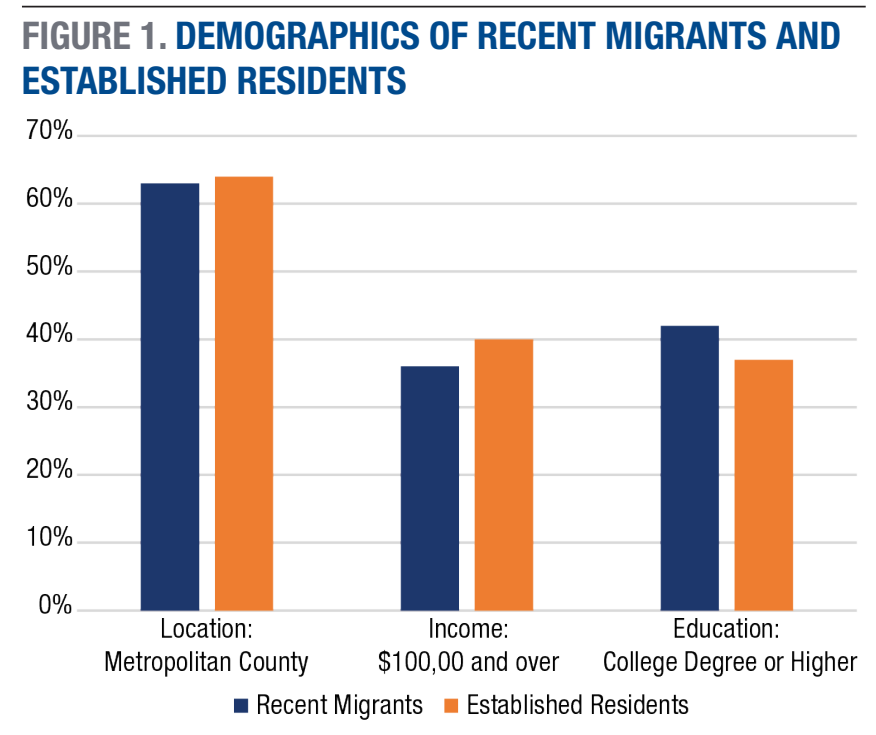

Source: Granite State Poll, University of New Hampshire

In terms of the age distribution, recent migrants are younger than established residents (Figure 2). Among those who arrived in the past ten years, 61 percent are younger than 50, compared to only 40 percent of established residents. This finding is consistent with prior research suggesting that migrants to the state tend to be younger than long-term residents, and it negates the assumption that migrants are all retirees moving into amenity-rich, remote areas. Although there are some older migrants to the state, recent migrants are generally younger.

\section{FIGURE 2. AGE DISTRIBUTION OF RECENT MIGRANTS AND ESTABLISHED RESIDENTS}

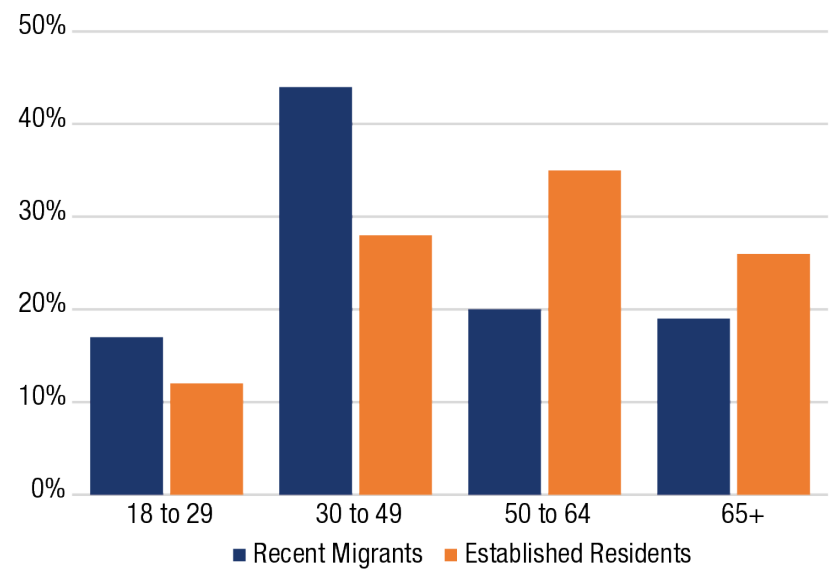

\section{Reasons for Migration Decisions}

Migration patterns are impacted not just by people moving into the state but also by those who remain here and by those who leave. ${ }^{7}$ To better understand this, we examine recent migrants' top three reasons for moving to New Hampshire and established residents' top three reasons for staying in the state rather than moving out. We grouped their responses into thematic categories (see Box 1 for details). ${ }^{8}$ The top seven reasons provided are family, the natural environment, quality of life, employment, taxes, culture and lifestyle, and the economy (Figure 3 ). ${ }^{9}$

\section{FIGURE 3. TOP REASONS TO STAY IN OR MOVE TO NEW HAMPSHIRE}

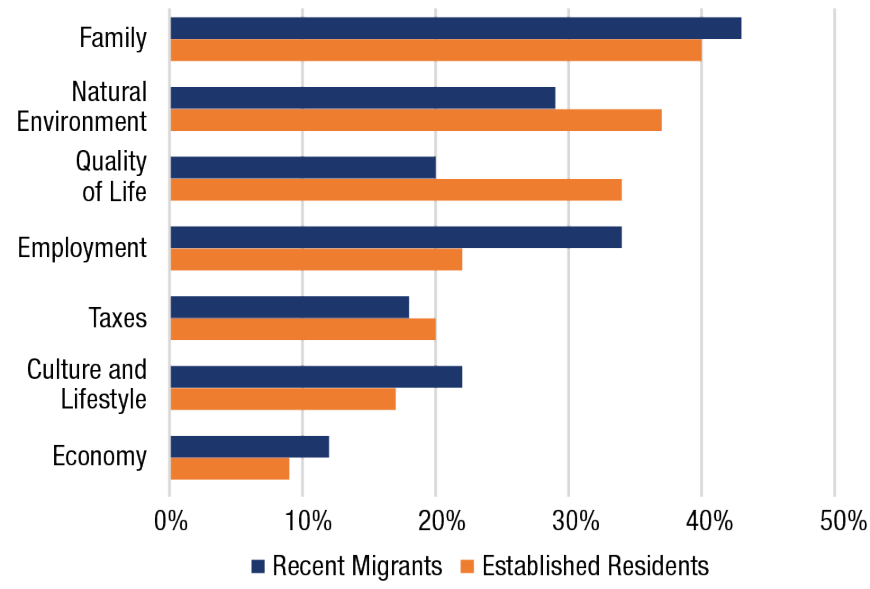

Source: Granite State Poll, University of New Hampshire

Both recent migrants to New Hampshire and established residents offer similar reasons for residing in the state. Both groups are motivated by their families and by New Hampshire's natural environment. Family is the most frequently mentioned among both recent migrants and established residents as one of their top three reasons, indicating that a high proportion of people make migration decisions-either to come or not to leave-based on their proximity to and relationships with family.

The second top reason for established residents was the natural environment, a choice that underscores the importance people who have lived in New Hampshire for over ten years place on their strong connection to the state's natural amenities, including its climate, seasons, lakes, mountains, forests, and seacoast. Many recent migrants (29 percent) were drawn to the state by its natural environment as well.

Source: Granite State Poll, University of New Hampshire 
Over a third of established residents and a fifth of recent migrants cite quality of life as another important reason to remain in the state. Many established residents mention that living in New Hampshire has made them appreciate its safety, its small-town feel, and its slower pace of life. It is also important to incoming migrants, as quality of life is mentioned by 20 percent of recent migrants.

Among recent migrants, employment ranks second, after family, as a reason for moving to the state; over a third cite it among their top reasons. In contrast, less than a quarter of established residents cite employment as a top motivation to remain. This underscores employment's important role as a "pull factor" that attracts migrants to the state.

Taxes, culture and lifestyle, and the economy are other factors mentioned less frequently for moving to or staying in the state. They are similarly valued among both recent migrants and established residents.

This comparison illustrates the similarities between what draws migrants to New Hampshire and what encourages residents to remain. Among both groups, family is mentioned more often than any other reason. There are differences between the two groups as well. For example, the natural environment and quality of life are more important among long-term residents, while employment is a much more significant draw for recent migrants.

\section{Box 1: Top Reasons to Come and to Stay in New Hampshire}

We created the top categories for coming to/staying in New Hampshire by coding nearly 4,300 open-ended responses into emergent themes. The following examples illustrate how we categorized the open-ended responses into the top seven reasons to move to and stay in New Hampshire:

\section{Family}

- "Being closer to children and grandkids."

- "Because I married a woman from Berlin, $\mathrm{NH}$, and she doesn't want to live anywhere else. Now she's in a nursing home, and I'd hate to leave her."

\section{Natural Environment}

- "I love the fact that there are mountains, lakes, and seacoasts. It's just beautiful."

- "So many different things to do: beach, biking, sailing, hiking."

\section{Quality of Life}

- "Familiarity, convenience, and slower pace of life."

- "I live in a rural neighborhood and the quality of life is good."

\section{Employment}

- "I started a business here."

- "Job opportunity near Boston."

Taxes

- "I like the tax policies that are in New Hampshire."

- "The lack of income and sales tax."

\section{Culture and Lifestyle}

- “The New England culture."

- "Wonderful people here. People genuinely are nice and polite."

\section{Economy}

- "Continues to be more affordable than Massachusetts."

- "It has a good economy." 


\section{Reasons for Migration Decisions by Age}

Migration decisions are patterned by how respondents say they value the seven factors above, but they are also influenced by the characteristics of the decision-makers. Figure 4 shows the difference in top reasons to move to/stay in New Hampshire for recent migrants and established residents under 50 years old compared to those 50 years and older.

Family is an important factor in migration decisions for recent migrants regardless of age: 42 percent of recent migrants under 50 and 44 percent of those 50 and older mention it as a reason they moved to New Hampshire. Employment is referenced more often by recent migrants under age 50 (38 percent) than by those over 50 (28 percent). The natural environment, quality of life, and taxes are more likely to be influential among recent migrants 50 and older, whereas culture and lifestyle is more of a draw for recent migrants under 50. Small shares of each age group cite the economy as a reason for moving to $\mathrm{New}$ Hampshire.

Among established residents, family, the natural environment, and quality of life are the top three reasons mentioned overall, but responses vary by age. Nearly half of the younger established residents cite family as a top reason to remain in the state, compared to only 36 percent of established residents 50 years and older. Conversely, quality of life is mentioned by 38 percent of older established residents, compared to only 27 percent of those under 50 . There is little difference between the two age groups in how often they mention the natural environment, employment, taxes, culture and lifestyle, or the economy.
These findings suggest that, though there is widespread agreement on the factors affecting migration decisions, age does matter, as it reflects where people are in the lifecycle. Given the importance of family and employment for younger residents, the findings suggest that starting careers and living near extended family may bear more weight among this group. For older residents, important decisions may include when and where they retire, how close they are to their children and grandchildren, and whether they should leave communities in which they have deep ties. Clearly, factors like the natural environment are important across ages for both recent migrants and established residents. However, age differences are evident for factors like employment and culture and lifestyle only among recent migrants, whereas family ties are more influential among younger established residents than among older longtime residents.
FIGURE 4. MIGRATION DECISIONS BY AGE

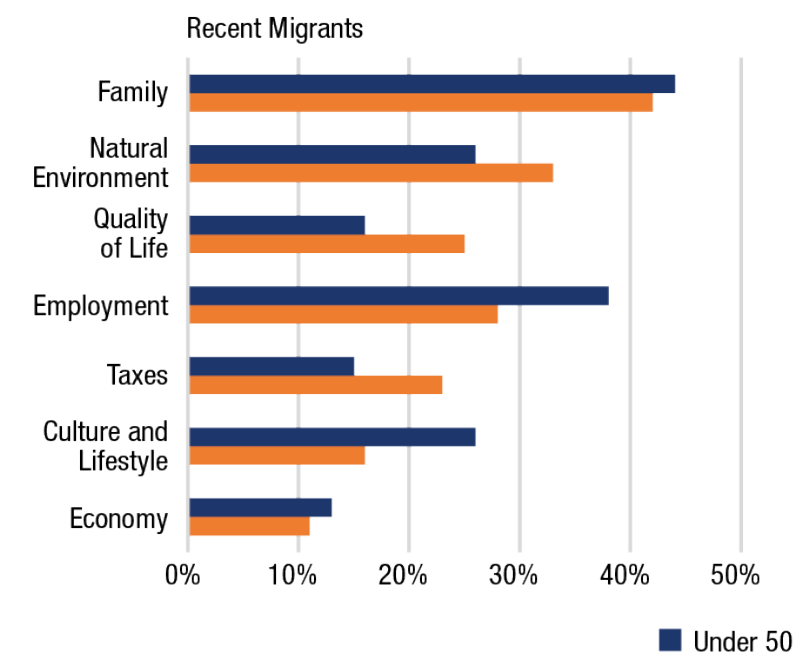

Source: Granite State Poll, University of New Hampshire

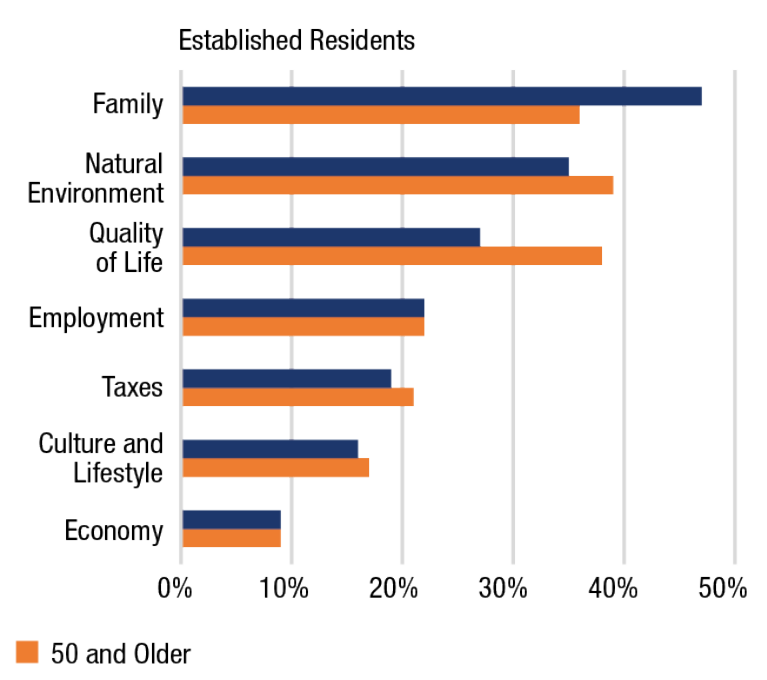


Reasons for Migration Decisions by Educational Attainment

Educational attainment is also related to which factors motivate migration decisions (Figure 5). Top reasons for recent migration, including family, the natural environment, and quality of life, did not vary by education. However, 46 percent of recent migrants with a college degree or higher mentioned employment, compared to only a quarter of recent migrants with no college degree. Conversely, 28 percent of recent migrants with lower educational attainment mentioned culture and lifestyle, compared to just 14 percent of those with a college degree. The economy was also referenced by 15 percent of recent migrants with no college degree compared to only 8 percent of recent migrants with higher educational attainment.

Among established residents, family, the natural environment, and quality of life were top reasons for staying in New Hampshire for both education groups. However, the natural environment and quality of life were mentioned more often among those with higher educational attainment. Mention of employment reflects the greatest variation across the groups, as 30 percent of established residents in the higher education group mentioned it compared to only 17 percent among those with lower educational attainment.

These findings illustrate how educational attainment relates to the factors motivating migration decisions. Of the top seven categories, employment has the greatest difference across education among both recent migrants and established residents.

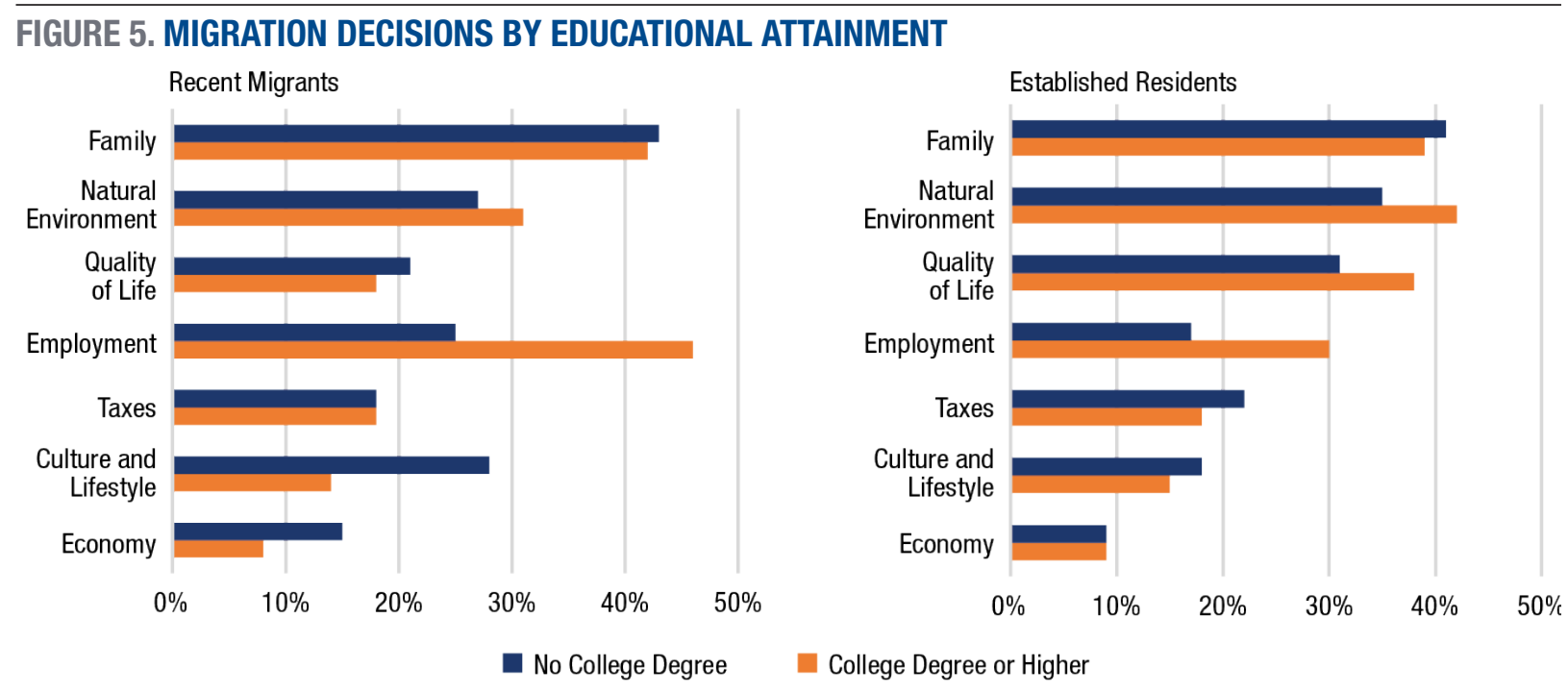

Source: Granite State Poll, University of New Hampshire 


\section{Reasons for Migration Decisions by Income Bracket}

Like educational attainment, people's household income is related to their migration decisions. Figure 6 illustrates how the top reasons that drew recent migrants and retained established residents in New Hampshire vary by annual household income bracket: under $\$ 45,000, \$ 45,000$ to $\$ 99,999$, and $\$ 100,000$ and over.

Among recent migrants, migration decisions vary greatly by income. Family, which is the top reason across all income groups, was mentioned by nearly half of recent migrants in the lowest and top income brackets but by only 30 percent in the middle-income category; this group was more likely to cite the natural environment. ${ }^{10}$ Employment and taxes' impact on moving to $\mathrm{New}$ Hampshire increased with each income bracket. Conversely, the economy is mentioned more often by people in lower-income households. Quality of life and culture and lifestyle have more mixed results across income levels.

Among established residents, family, the natural environment, and quality of life remain the top reasons for people to remain in New Hampshire, with only modest variation across the income categories. Quality of life is mentioned slightly more often by lower-income established residents compared to others. Employment and taxes are mentioned more often by people in higher-income brackets and least often by those in low-income households. Culture and lifestyle and the economy show only modest differences across income brackets for established residents.

Overall, there is less variation by income level among established residents than among recent migrants. This suggests that people in different income brackets have different motivations to migrate but relatively similar reasons to remain. However, factors like employment and taxes were more commonly referenced by people in higher-income households across both recent migrants and established residents.

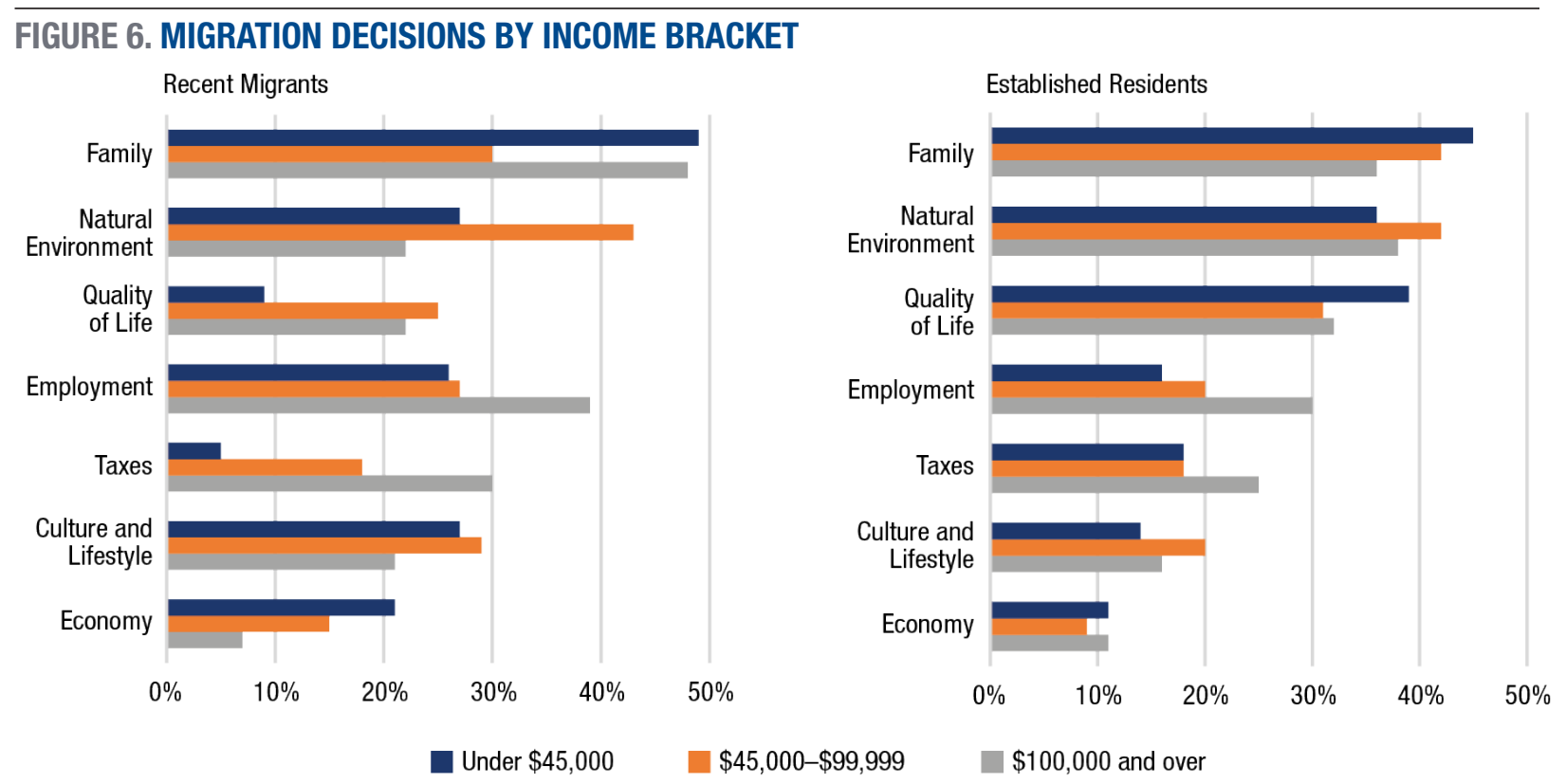

Source: Granite State Poll, University of New Hampshire 


\section{Conclusion}

In recent years, migration has accounted for virtually all the growth in New Hampshire's population. Our findings illustrate that migration decisions-both whether to stay in New Hampshire or migrate to it-are influenced by an interrelated set of factors that encompass elements of the state's social, economic, and natural environment.

Family and the natural environment are the top reasons that people move to and stay in the Granite State. Employment is also important, particularly to many younger, well-educated, and higherincome migrants. In contrast, New Hampshire's quality of life motivates many current residents to remain. Taxes, culture and lifestyle, and the economy also play into migration decision-making among modest shares of both recent migrants and longtime residents.

Policymakers may be able to influence some of the factors that encourage residents to stay in the state and attract new migrants to it, such as by creating housing opportunities for young people who moved to New Hampshire for work, retaining tax structures that keep residents from moving to high-tax states, and investing in natural environment amenities that draw and retain residents. However, our findings suggest that there is no single solution to developing policy that draws and retains New Hampshire residents. In fact, policies that support some factors might directly undermine others, such as natural conservation rules that impact the ability of businesses to expand or the ability of early-career young adults to find affordable housing.

Prior research on migration motivations underscores that certain features may act as pull factors for some people and push factors for others. For example, a study of emerging adults' perceptions of the benefits and barriers to living in Coös County, $\mathrm{NH}$, found that employment opportunities are plentiful for particular professions and lacking for others, and close social ties are comforting to some people and stifling to others. ${ }^{11}$ Similarly, different regions of New Hampshire provide distinct environments and opportunities that may draw or retain residents. Thus, any policy initiative aimed at affecting migration must understand that the reasons people move to or stay in a state are complex and interrelated, and they can vary by personal characteristics, experiences, and location.

New Hampshire is a small state, but our research demonstrates that a complex matrix of social, economic, and environmental factors influences decisions to migrate to the state or remain in it. Most of these same factors are relevant to migration decision-making elsewhere in the United States. In the case of New Hampshire, its proximity to a large urban area, the attractiveness of its natural amenities, and its mix of rural, suburban, and urban areas contributes to a better understanding of the motivations behind migration decisions in other states as well as in New Hampshire.

\section{Data}

Data were collected by the University of New Hampshire Survey Center's Granite State Poll, a quarterly survey administered by telephone to New Hampshire residents using random-digit dialing. From summer 2018 to fall 2019, 2,063 respondents were asked their top three reasons for staying in New Hampshire rather than moving to a different state and, if relevant, the top three reasons they initially moved to the state. The questions were open ended, allowing respondents to offer their answers without constraining them to a pre-determined list.

The data were thematically coded into emergent categories and subcategories based on why people moved to or stayed in New Hampshire. The nearly 4,300 responses fell within eighteen overarching categories, with seven categories representing the majority of responses. There are several subcategories under each of these eighteen main categories based on key words and key concepts, so there is no overlap across the themes. Respondents were grouped into two categories. Recent migrants include those who moved to New Hampshire in the past ten years. Established residents have lived in New Hampshire for more than ten years, and they include lifelong residents and those who moved to New Hampshire more than ten years ago. The sample included 244 recent migrants and 1,819 established residents, and the data were weighted to properly represent various subgroups of New Hampshire's population. 


\section{Endnotes}

1. Kenneth M. Johnson, "New Hampshire Population Grew Last Year, Even Though Deaths Exceeded Births," Data Snapshot (Durham, NH: Carsey School of Public Policy, University of New Hampshire, 2020).

2. Kenneth M. Johnson, Dante J. Scala, and Andrew Smith, "First in the Nation: New Hampshire's Changing Electorate in Changing Times," Regional Issue Brief No. 60 (Durham, NH: Carsey School of Public Policy, University of New Hampshire, 2019).

3. Kenneth M. Johnson, "New Hampshire Demographic Trends in an Era of Economic Turbulence," Regional Issue Brief No. 59 (Durham, NH: Carsey School of Public Policy, University of New Hampshire, 2019).

4. Johnson, "New Hampshire Demographic Trends in an Era of Economic Turbulence" (2019).

5. Recent migrants' demographics are based on their current age, income, education, and location, not their characteristics at the time of moving to New Hampshire within the last decade.

6. Comparison Census data are from the 2018 American Community Survey five-year estimates (data not shown).

7. Though it would be helpful to know why people decided to leave the state, we have no information on outmigration.

8. Because each respondent could provide up to three reasons, the totals in the figures do not add up to 100 percent.

9. These seven categories were both top reasons people moved to New Hampshire as well as top reasons people stay in New Hampshire rather than moving to a different state. Avoidance of elsewhere, such as wanting to escape the city life or leave a high-tax state, was also a reason people moved to the state.

10. The middle-income group's frequent mentions of the natural environment and less frequent mentions of family are a perplexing finding. Further research is needed to understand the cause for this difference in migration priorities by income level.

11. Kristine Bundschuh, "The Benefits and Barriers to Living in Coös County, New Hampshire" (Durham, NH: Carsey School of Public Policy, University of New Hampshire, 2020).

\section{About the Authors}

Kenneth M. Johnson is senior demographer at the Carsey School of Public Policy, Class of 1940 professor of sociology at the University of New Hampshire, and an Andrew Carnegie fellow.

Kristine Bundschuh is a $\mathrm{PhD}$ student in sociology at the University of New Hampshire.

\section{A cknow ledgments}

This research was supported by the New Hampshire Agricultural Experiment Station in support of Hatch Multi-State Regional Project W-4001 through joint funding of the National Institute of Food and Agriculture, U.S. Department of Agriculture, under award number 1013434, and the state of New Hampshire. The content is solely the responsibility of the authors and does not necessarily represent the official views of the agencies supporting this research.

\title{
TI University of New Hampshire Carsey School of Public Policy
}

The Carsey School of Public Policy at the University of New Hampshire is nationally recognized for its research, policy education, and engagement. The school takes on the pressing issues of the twenty-first century, striving for innovative, responsive, and equitable solutions.

\author{
Huddleston Hall • 73 Main Street • Durham, NH 03824 \\ (603) $862-2821$ \\ TTY UsERS: DIAL 7-1-1 OR 1-800-735-2964 (RELAY N.H.) \\ carsey.unh.edu
}

